\title{
La embargabilidad en el régimen económico de las cooperativas de viviendas de Euskadi
}

(The seizability in the economic regime of the housing cooperatives of the Basque country)

\author{
Gotzon Gondra Elgezabal \\ Universidad de Deusto (España) \\ Xabier Núñez García² \\ Abogado (España)
}

Sumario: I. Introducción. II. Aportaciones de los socios en las cooperativas de viviendas: a) Cantidades desembolsadas como aportaciones a capital social. b) Cantidades desembolsadas a cuenta de adjudicación de vivienda. III. Estructura del Patrimonio Neto en las sociedades cooperativas, según la Ley vasca. IV. El embargo de los bienes y derechos en el Código Civil: breve acercamiento. V. Embargabilidad de las aportaciones y fondos obligatorios en las cooperativas de viviendas de Euskadi. VI. Conclusiones. VII. Bibliografía.

Summary: I. Introduction. II. Contributions of the members in housing cooperatives: a) Amounts disbursed as contributions to capital stock. b) Amounts disbursed on account of housing allocations (or other elements). III. Structure of Shareholders' Equity in cooperative societies, according to Basque Law. IV. Seizure of property and rights in the Civil Code: brief introduction. V. Seizability of the amounts disbursed and the mandatory funds in the housing cooperatives of the Basque Country. VI. Conclusions. VII. Bibliography.

Resumen: Las cooperativas de viviendas tienen varias particularidades respecto al resto de clases de cooperativas, destacando entre ellas el régimen económico de las cantidades desembolsadas por los socios. Aportaciones que llevan aparejado un reflejo contable determinado, con afección directa sobre el Patrimonio Neto de la sociedad, que resulta además diferente al de otros tipos jurídicos societarios. Cuestiones que, irremediablemente, afectan al régi-

1 Profesor de Derecho Mercantil de la Universidad de Deusto; Abogado-Abokatua; Letrado asesor de la Federación de Cooperativas de Viviendas-BIZIKOOP. Correo electrónico: gotzon.gondra@deusto.es.

2 Abogado-Abokatua. Correo electrónico: xabiernunez@opendeusto.es. 
men de responsabilidad de la propia sociedad y de los socios que la conforman frente a las deudas con terceros acreedores. Así, regulando la Ley vasca el carácter embargable o no de aquéllas partidas que conforman el Patrimonio Neto, se estima interesante el estudio de la embargabilidad de las aportaciones desembolsadas por los socios, formen o no éstas parte del mismo.

Palabras clave: Socio, Aportaciones, Patrimonio, Responsabilidad, Embargo

Abstract: Housing cooperatives have several distinctive features with respect to the other types of cooperatives, in particular, the economic regime of the amounts disbursed by their members. These contributions carry a specific accounting record, with a direct effect on the Shareholders' Equity of the Society, which is also different from that in other types of societies. Such issues inevitably affect the liability regime of the cooperative society and the members that comprise it against debts with third-party creditors. Thus, taking into consideration that the Basque Law regulates the seizable or non-seizable nature of the items that make up the Shareholders' Equity, it is interesting to study the seizability of the contributions disbursed by the members whether or not they add to the Equity.

Keywords: Member, Contributions, Equity, Liability, Seizure 


\section{Introducción}

Las cooperativas de viviendas se han consolidado en Euskadi y en el conjunto del Estado como una alternativa al acceso a la vivienda, incrementándose este modelo de promoción de viviendas durante estos últimos años. Su justificación se ve reflejada, entre otros motivos, en el ahorro que supone para el socio el prescindir de la intervención de una promotora profesional y la restricción del crédito a la población por parte del sector financiero. ${ }^{3}$

Los expertos venían haciéndose eco de una eventual y previsible nueva crisis a nivel mundial, con afección a los distintos sectores económicos, entre otros el inmobiliario, como consecuencia del padecimiento de la economía familiar. Y todo hace indicar que aquella crisis se ha podido ver acelerada e incluso incrementada por la actual situación provocada por el COVID-19. Es decir, las cooperativas de viviendas y sus socios se verían afectados por esta crisis debido, entre otras causas, a la disminución de la concesión de crédito, el descenso del consumo y de la inversión, la falta de liquidez de la empresa, las consecuencias jurídico laborales que afecten a los socios a consecuencia del Covid-19 (concretamente los ERTEs, los cuales muchos derivarán probablemente en EREs). Situación que, como consecuencia de la minoración o falta de ingresos inicialmente previstos puede derivar en impagos de los socios hacia la cooperativa y de ésta respecto a las constructoras e instituciones, incrementándose el peligro de impago de éstos hacia sus acreedores.

En este sentido, y en relación con el régimen de responsabilidad, surge la duda de si cabe la posibilidad de que los acreedores, tanto de la cooperativa como de los propios socios, pueden embargar las cantidades que ingresan los socios a la cooperativa en caso de no poder cobrar sus derechos de crédito por la insolvencia de sus respectivos deudores.

La embargabilidad de las aportaciones de los socios en las cooperativas cobra especial relevancia en este tipo de cooperativas por diversos motivos. Por una parte, la condición de socio está vinculada a menudo al hecho familiar, entendido como unidad convivencial, estando supeditado este último enormemente al devenir de dichas aportaciones, debido al impacto elevadísimo que supone para la economía familiar las cantidades que el socio entrega a cuenta para la fi-

3 Etxezarreta Etxarri, A. y Merino Hernández, S. «Las cooperativas de vivienda como alternativa al problema de la vivienda en la actual crisis económica». Revesco: Revista de Estudios Cooperativos, núm. 113, 2014, p. 104. 
nanciación de la adjudicación de su vivienda, por ser éstas cuantiosas, aspecto en el que se profundizará más adelante en el presente artículo.

Por otra parte, la embargabilidad no supone un riesgo solamente para el socio que ha aportado esas cantidades, sino también para la cooperativa en sí y, por ende, para los demás socios que la conforman junto con aquel, pudiendo, por un lado, acarrear problemas de financiación para el oportuno y debido desarrollo de la actividad promocional y, por otro lado, afectar a las cantidades aportadas por los demás socios pudiendo venir éstos obligados a realizar más desembolsos de capital —aportaciones - que las iniciales para poder llevar a cabo la adjudicación de viviendas y/o el pago de las deudas contraídas, precisamente por esa necesidad de autofinanciación, al menos parcial, inherente a las cooperativas de viviendas, en su condición de autopromotores.

El presente artículo pretende ahondar en la problemática del eventual embargo de los fondos obligatorios y de las cantidades depositadas por los socios en las cooperativas de viviendas de Euskadi. Para ello, es imprescindible examinar, antes de nada, los límites de la embargabilidad establecidos en el Código Civil para, a continuación, analizar los límites desde el punto de vista del régimen de responsabilidad de la cooperativa y de sus socios en la reciente Ley 11/2019, de 20 de diciembre, de Cooperativas de Euskadi (en adelante LCE), y finalizar este estudio centrándolo en el régimen económico y la embargabilidad de las distintas dotaciones que la pueden conformar en las cooperativas de viviendas de Euskadi.

\section{Aportaciones de los socios en las cooperativas de viviendas}

a) Cantidades desembolsadas como aportaciones a capital social

Las cooperativas de viviendas, a tenor de lo dispuesto por el artículo 117 de la LCE:

«tienen por objeto procurar a sus personas socias viviendas o locales, edificaciones e instalaciones complementarias; mejorar, conservar y administrar dichos inmuebles y los elementos, zonas o edificaciones comunes; crear y prestar los servicios correspondientes, así como rehabilitar viviendas, locales y edificaciones e instalaciones destinadas a las personas socias.» 
Aun así, estas cooperativas normalmente se constituyen básicamente para proporcionar viviendas o locales a sus socios. ${ }^{4}$ El principal factor atractivo de este modelo es la ausencia de la figura del promotor externo, adquiriendo dicha función los socios y, por ende, procurando éstos ahorrar los costes derivados del beneficio empresarial del promotor inmobiliario. ${ }^{5}$ Aún así, hay que tener en cuenta que el gasto que debe asumir el socio es el que deriva del riesgo empresarial que adquiere. Es decir, ser socio implica actuar como un empresario, participando en la gestión de la sociedad, esto es, arriesgando el dinero entregado en la cooperativa y teniendo que afrontar las hipotéticas pérdidas y sobrecostes, ya que una cooperativa es una empresa al fin y al cabo. ${ }^{6}$

Las aportaciones que deben realizar los socios de las cooperativas de viviendas se pueden dividir en tres apartados. Por una parte, nos encontraríamos con la cuota de ingreso (la cual se destina al Fondo de Reserva Obligatorio - en adelante FRO-) y las sanciones (las cuales se destinan a la Contribución para la educación y promoción cooperativa y otros fines de interés público —en adelante COFIP-), aportaciones que serán analizadas en el siguiente epígrafe de este trabajo.

Por otra parte, tendríamos también las aportaciones de los socios al capital social, desembolsadas en concepto de aportación, básicamente obligatoria para adquirir la condición de tal socio. Éstas cantidades se ingresan como capital social de la cooperativa, formando parte del Patrimonio Neto de la misma, y quedan supeditadas al riesgo comercial inherente a la propia actividad cooperativizada. ${ }^{7}$ Pero no debemos equiparar capital social a Patrimonio Neto, por cuanto éstos resultarán coincidentes en el momento de la constitución de la sociedad, pero una vez iniciado el desarrollo de la actividad el valor del Patrimonio Neto podrá verse modificado como consecuencia del resultado que se derivase de aquella actividad, aún cuando las aportaciones a capital social se mantuvieren inamovibles. ${ }^{8}$

4 Gadea Soler, E. Derecho de las cooperativas: Análisis de la Ley 4/1993, de 24 de junio, de cooperativas del País Vasco, Universidad de Deusto, Bilbao, 2001, p. 268.

5 Merino Hernández, S. "Realidad de las cooperativas de viviendas en la Comunidad Autónoma del País Vasco». Revista Vasca de Economía Social. núm. 15, 2018, p. 280.

${ }^{6}$ Gondra Elguezabal, G. «Euskadiko Etxebizitza Kooperatibak (iruzkinak)». Revista Vasca de Economía Social, núm. 0, 2004, p. 120.

7 Puy Fernández, G. «Naturaleza de los bienes susceptibles de ser aportados al capital social cooperativa andaluza». Trabajo: Revista iberoamericana de relaciones laborales. n. ${ }^{\circ}$ 4, 1998, pp. 147-148.

8 Gadea Soler, E. Manual de Derecho de Sociedades Cooperativas. Universidad del País Vasco junto con el Consejo Superior de Cooperativas de Euskadi, Vitoria, 2008, p. 158. 
El capital social tiene una función de garantía, pero limitada al capital mínimo exigido por la Ley o por los Estatutos de la cooperativa, por el hecho de que dicha cantidad puede variar debido al principio de puertas abiertas. ${ }^{9}$ Remarcar la singularidad de las cooperativas que, a diferencia de las sociedades mercantiles, son Sociedades de capital variable consecuencia de dicho principio. Mientras que en estas últimas es necesaria la modificación de los estatutos, en las cooperativas el capital puede variar sin necesidad de modificar éstos. El capital aumentará cuando ingrese un nuevo socio y disminuirá con la separación o expulsión. ${ }^{10}$

La LCE en su art. 60 dispone que el capital social de la cooperativa estará constituido por aportaciones realizadas por los socios, tanto obligatorias como voluntarias, con derecho de reembolso o cuyo reembolso puede ser rehusado por la asamblea o el consejo rector, o dinerarias o no dinerarias.

Por lo que concierne a las aportaciones obligatorias, su fin es dotar a la cooperativa de los recursos suficientes para llevar a cabo su actividad cooperativizada. ${ }^{11}$ La aportación mínima exigida es relevante, ya que la cuantía exigida debe fijarse teniendo en cuenta que el conjunto de aportaciones obligatorias deben constituir una cifra de capital adecuada para la empresa.» ${ }^{12}$ Dicha importancia se ve reflejada en el artículo 61.2 de la LCE, disponiendo que la aportación obligatoria, sin importar que sea dineraria o no dineraria «deberá desembolsarse, al menos, en un veinticinco por ciento en el momento de la suscripción, y el resto en el plazo que se establezca por los estatutos o la asamblea general, que como máximo será de cuatro años.»

Estas aportaciones, según el art. 61.1 de la LCE, son requisito necesario para obtener la condición de socio en la cooperativa, y pueden realizarse en el momento de constitución de la cooperativa, posteriormente por los nuevos socios que entren en la sociedad o por imposición mediante acuerdo adoptado por la Asamblea General, a tenor del art. 61.4 de la LCE. En caso de imposición, el socio disconforme puede darse de baja, en base al principio de puertas abiertas, considerándose ésta justificada, aunque la LCE en su art. 61.4 permite usar las aporta-

9 Gadea Soler, E. Derecho de las cooperativas... op. cit., p. 208.

10 Fajardo García, G. La gestión económica de la cooperativa: responsabilidad de los socios. Tesis Doctoral (Universidad de Valencia), Tecnos, Madrid, 1997, p. 21 [consulta: 23 de octubre de 2019]. Disponible en web: http://roderic.uv.es/handle/10550/38450.

11 Torres Pérez, F.J. Régimen Jurídico de las Aportaciones Sociales en la Sociedad Cooperativa. Aranzadi, Pamplona, 2012. p. 80.

12 Gadea Soler, E. Derecho de las cooperativas... op. cit., p. 209. 
ciones voluntarias preexistentes para cubrir nuevas aportaciones obligatorias y así evitar la baja del socio.

Por otro lado, las aportaciones voluntarias son aquellas aportaciones que integran el capital social de la cooperativa pero que, como su nombre bien indica, son de carácter voluntario. Dicho de otra manera, por una parte, aunque la Asamblea General adopte la decisión de suscribir dichas aportaciones, el socio que no desee hacerlo no podrá ser obligado a ello, y por otra parte, no son conditio sine qua non para ser miembro de la Sociedad aunque, al ser aportaciones sociales como las obligatorias, pueden ser utilizadas para sufragar las deudas de la empresa; es decir, tienen también como finalidad la autofinanciación para la consecución del objeto social. ${ }^{13}$ Todo ello sin perjuicio de señalar la posibilidad de la modificación del carácter voluntario de dichas aportaciones por parte de la Asamblea General, convirtiéndolas en obligatorias (y viceversa) e, incluso, en su caso, su eventual transformación en cantidades entregadas a cuenta para adjudicación de vivienda, con la consiguiente regularización contable (salida del Patrimonio Neto y reconocimiento como cuenta acreedora) y fiscal (sujetos al Impuesto Sobre el Valor Añadido —en adelante IVA- ...) que se derivaría de tal hecho.

En cuanto a las cooperativas de viviendas, el capital social es un componente financiero ínfimo, sobre todo si lo comparamos con las cantidades entregadas a cuenta para adjudicación de vivienda. » ${ }^{14}$ Por lo que normalmente la relevancia de inembargabilidad de las aportaciones de los socios en las cooperativas de vivienda no recae en las aportaciones integradas en el Capital social de la sociedad.

\section{b) Cantidades desembolsadas a cuenta de adjudicación de vivienda}

A su vez, los socios deben aportar las denominadas cantidades entregadas a cuenta para la adjudicación de su vivienda, es decir, cantidades que sirven para financiar la actividad cooperativa con el fin de adjudicar a los socios sus respectivas viviendas. Sobre estas cantidades, aunque la cooperativa deba gestionarlas y emplearlas para la financiación, promoción y construcción de las viviendas, ésta tiene libertad de disposición sobre ellas. ${ }^{15}$ Se debe señalar que no son

13 Gadea Soler, E. Manual de Derecho de Sociedades... op. cit., p. 160.

14 Merino Hernández, S. Manual de Derecho de Sociedades Cooperativas. Universidad del País Vasco junto con el Consejo Superior de Cooperativas de Euskadi, Vitoria, 2008, p. 345.

15 Fajardo García, G. La gestión económica de la cooperativa... p. 218. 
aportaciones al Capital social, no debiéndose contabilizar como recursos propios de la sociedad, sino recursos ajenos asimilables a una cuenta con socios o deudas con terceros. ${ }^{16}$

Es más, a diferencia del Capital social, en las cooperativas de viviendas las cantidades entregadas a cuenta suelen ser cuantiosas, suponiendo un gran esfuerzo económico para sus socios ${ }^{17}$. Y, a su vez, dichas cantidades son imprescindibles para poder llevar a cabo la construcción de las viviendas, siendo sumamente importante su desembolso para la cooperativa y el conjunto de los socios; enmarcado dentro de la actividad auto promocional. Por lo que el estudio sobre la eventual embargabilidad de estas cantidades cobra especial relevancia en esta clase de cooperativas.

Destaca también, desde un punto de vista contable, que estas cantidades entregadas por parte de los socios a cuenta de la adjudicación de su futura vivienda deberán figurar en el pasivo del balance, dentro de una cuenta contable de "acreedores a largo plazo», manteniéndose como tal incluso en el supuesto de que alguno de ellos causare baja voluntaria, atendiendo al régimen de reembolso legalmente establecido. En este sentido, dispone el art. 119.6 de la LCE que el reembolso de estas cantidades procederá en el momento en el que otra persona se subrogue en su posición (derechos y obligaciones), quedando sujeto por tanto a un plazo indeterminado que invita, en aplicación del criterio de prudencia, a mantener las cantidades desembolsadas por el socio saliente para la adjudicación de vivienda en la mencionada cuenta, a la que se pasarán también, inicialmente, las aportaciones obligatorias para adquirir la condición de socio. Hecho que lleva también a la discusión meta jurídica, por cuanto jurídicamente se encuentra resuelto, tal y como a continuación expondremos, del deber de los socios de constituir garantía sobre esas aportaciones por ellos mismos desembolsadas y gestionadas, viniendo por tanto obligados a incurrir en el gasto financiero inherente a dicha operación.

La Ley 38/1999, de 5 de noviembre, de Ordenación de la Edificación, en su Disposición adicional primera, establece la obligatoriedad de garantizar las cantidades entregadas a cuenta en las cooperativas mediante aval solidario emitido por entidades de crédito o contrato de seguro de caución suscrito con entidades aseguradoras, teniendo

16 Merino Hernández, S. Manual de Derecho de Sociedades... op. cit., pp. 345-346.

17 Gondra Elguezabal, G. y Bilbao Zorrozua, A. "Alcance del régimen de responsabilidad de los socios en las cooperativas de viviendas en Euskadi». Revista Vasca de Economía Social, núm. 16, 2019, p. 155. 
ambas la obligación de estar debidamente autorizadas para operar en España.

Este deber de entregar garantía suficiente es legalmente obligatorio en las cooperativas, aunque parece no tener mucho sentido, ya que esto implica que la persona socia deba avalar las aportaciones por ella misma desembolsadas, incurriendo en un gasto más, a diferencia del caso de exigir a un promotor externo dicha garantía, el cual sí cobra sentido ya que éste gestiona cantidades ajenas. Parece lógico concluir que el hecho de avalar o garantizar las aportaciones de los socios debiera ser voluntario, por lo que podría deducirse que si legalmente es obligatorio, se debe al convencimiento del legislador de que en numerosas ocasiones las promoción bajo fórmula cooperativa se lleva a cabo a través de otros agentes: gestoras de cooperativas de vivienda, consultoras inmobiliarias... No podemos ser ajenos al hecho de que no resulta fácil que varias personas coincidan con los mismos intereses autopromocionales, lo que implica una labor de comercialización previa por parte de terceros, a fin de conseguir captar a personas interesadas en adquirir la condición de socios adjudicatarios. Cuestión sobre la que el legislador ha pretendido y logrado incidir sustancialmente en el art. 119 de la LEC, cuando condiciona la propia constitución de la cooperativa a que venga conformada de inicio por al menos el $50 \%$ de los socios adjudicatarios que requerirá la sociedad en su proyecto promocional. Sin perjuicio de que ese mismo hecho conlleve también la obligatoriedad de la existencia de un proyecto promocional al menos inicial, desarrollado con carácter previo a la constitución.

Hay que tener en cuenta que, a su vez, para que no haya un enriquecimiento injusto por parte de los socios a la hora de adjudicarles las viviendas, los socios deberán soportar los gastos producidos en la construcción de las viviendas y los incrementos de precio de las viviendas por aumento de gastos proporcionalmente a la cuota de cada uno en la sociedad, en caso de que la cooperativa no sea solvente para hacer frente a esas deudas ${ }^{18}$, pudiendo elevarse considerablemente el gasto al que deben hacer frente. El concepto de cuota ha de entenderse como actividad cooperativizada, que habitualmente se determina por el precio y/o metros cuadrados de los elementos de los que hubieran resultado adjudicatarios. Normalmente el precio se fija en función de los referidos metros, además de alturas, ubicación de la vivienda y ane-

18 Lambea Rueda, A. Cooperativas de viviendas. Promoción, construcción y adjudicación de la vivienda al socio cooperativo, Comares, Granada, 2012, p. 349. 
jos en la edificación... Los criterios utilizados son los comúnmente empleados en el sector inmobiliario.

\section{Estructura del Patrimonio Neto en las sociedades cooperativas, según la Ley vasca}

Respecto al régimen económico de las cooperativas de Euskadi, el objetivo de la Ley vasca es fortalecer empresarialmente a estas sociedades, regulando tanto las aportaciones obligatorias como voluntarias y nuevas fórmulas de financiación, teniendo presente, a su vez, la protección de terceros por medio de garantías, regulando el sistema de imputación de pérdidas, por ejemplo. ${ }^{19}$

Antes de nada, con respecto a la entrada en vigor de la nueva Ley 11/2019, de 20 de diciembre, de cooperativas de Euskadi (en adelante LCE), hacer hincapié en que no ha variado el régimen económico, respecto a la Ley anterior, de las cantidades depositadas por los socios en el patrimonio de la cooperativa. La única modificación introducida ha sido en relación con el límite de imputación de las pérdidas al FRO, como bien se refleja en el séptimo punto de la exposición de motivos de la LCE.

Adentrándonos en lo que se pretende investigar en el marco del presente apartado, el Patrimonio Neto de las cooperativas, como todas las sociedades, está conformado por el Capital social, el cual se constituye y conforma, tal como se ha venido a explicar en el anterior epígrafe de este artículo, con las aportaciones obligatorias y voluntarias de las personas socias, siendo las cooperativas de viviendas sociedades con Capital social normalmente simbólico, cumpliendo el mínimo legalmente establecido, sin perjuicio de la actividad promotora que fueran a desarrollar. Estas aportaciones, como todas las contribuciones societarias a Capital social, no están sujetas al IVA ya que no son un desembolso destinado para la posterior adquisición de un bien o prestación de un servicio 20 , y es por ese mismo razonamiento que el resto de aportaciones dinerarias destinadas a financiar

19 Gadea Soler, E. Derecho de las cooperativas: Análisis de la Ley 4/1993, de 24 de junio, de cooperativas del País Vasco, Universidad de Deusto, Bilbao, 2001, p. 201.

20 La Dirección General de Tributos en la consulta n. ${ }^{\circ}$ 2077/2033 de 4 de diciembre de 2003 advierte que en las cooperativas de viviendas, ocasionalmente, las aportaciones al capital social pueden estar sujetas a IVA cuando se desembolsan como pagos anticipados efectuados a cuenta de las futuras entregas de viviendas que realizará la cooperativa para la persona socia. 
la adjudicación de vivienda sí que están sujetas al referido impuesto, ya que se consideran pagos anticipados a la entrega de la vivienda realizados a una empresa, devengando el IVA en el momento que los socios desembolsen estas aportaciones, a tenor de cuanto dispone el art. 75 de la Ley 37/1992, de 28 de diciembre, del Impuesto sobre el Valor Añadido.

Junto a las aportaciones a Capital social, la LCE establece como parte del Patrimonio Neto la posibilidad de la existencia de dos fondos obligatorios, cuyo régimen dotacional y de aplicabilidad procura regular, en mayor o menor grado, la propia legislación. Obligatoriedad dotacional que es ajena a las particularidades que pudieran derivarse de las distintas clases de cooperativas, incluidas las de viviendas. Es decir, se estima importante señalar que la regulación del régimen económico contenida en la LCE es genérica, al margen de las especificidades que más adelante se procuran para cada clase de cooperativa.

La ley hace referencia, por una parte, al FRO, el cual está destinado, según el art. 71 de la LCE «a la consolidación, desarrollo y garantía de la cooperativa.», vale decir, a la promoción de la actividad de la sociedad y a la conservación de la cooperativa.

El FRO desempeña básicamente dos funciones ${ }^{21}$, las cuales son necesarias para cumplir el cometido de este Fondo, dado que, por una parte, sirve a la cooperativa para autofinanciarse y aumentar los recursos propios y, por otra parte, las cantidades ingresadas actúan como garantía para los acreedores y para la sociedad en sí, ya que proporciona un margen de reacción frente a situaciones de crisis económicas al compensar con este Fondo, en caso de no existir otras reservas, las pérdidas del ejercicio, a tenor de cuanto dispone el art. 73 de la LCE.

Desde un punto de vista contable, el FRO vendrá reflejado en el patrimonio neto en el pasivo del balance de la cooperativa, resultando irrepartible entre las personas socias (excepto en los supuestos expresamente previstos en la LCE). ${ }^{22}$ Atendiendo a la regulación contenida en relación al régimen económico, el destino de este Fondo se circunscribe básicamente a la compensación de pérdidas, con los lí-

21 Alzola Berriozabalgoitia, I. y Esnaola Etcheverry, J.M. Manual de Derecho de Sociedades Cooperativas, Universidad del País Vasco junto con el Consejo Superior de Cooperativas de Euskadi, Vitoria-Gasteiz, 2008, p. 184.

22 Los estatutos de las cooperativas mixtas, con la autorización del Consejo Superior de Cooperativas de Euskadi, pueden prever que sea repartible en caso de liquidación (art. 155.7 LCE). 
mites porcentuales legalmente establecidos. Posibilidad, la de la imputación de pérdidas con cargo a dicho Fondo que resulta lícita aun cuando pudieran existir otras reservas disponibles para ello. Límite legal que se ha visto flexibilizado respecto a la normativa anterior, disponiendo el art. 73.1 apartado b) de la LCE como imputación máxima el resultante de aplicar el porcentaje medio de lo destinado a los fondos legalmente obligatorios en los últimos cinco años de excedentes positivos, o desde su constitución si esta no fuera anterior a dichos cinco años (regulación ya contenida en la ley derogada), excepto en el supuesto de que el FRO superase el cincuenta por ciento del capital social de la cooperativa, en cuyo caso el importe que exceda de dicho porcentaje se podrá también emplear para compensar las pérdidas (novedad contenida en la nueva LCE).

En caso de acordarse la imputación de las pérdidas con cargo al FRO, se procederá a cargar en la cuenta en la que se refleje el Fondo directamente la cuenta representativa de las pérdidas a compensar. Lo que en caso alguno implica ni debe interpretarse como obligación de mantener las cantidades dotacionales del FRO como inamovibles, por ejemplo, en una cuenta corriente titularidad de la empresa y bajo dicha denominación, sin posibilidad alguna de disponibilidad de aquellos Fondos por parte de los administradores de la cooperativa. Es decir, pueden estos administradores hacer uso libremente de todos aquellos importes que forman parte de la liquidez —-tesorería- de la cooperativa en el tráfico corriente de la sociedad, con la finalidad de adquirir bienes o prestar servicios imprescindibles para la actividad empresarial, a diferencia de cuanto sucede con el otro Fondo obligatorio, tal y como a continuación expondremos. Es decir, la compensación de las pérdidas con cargo al FRO se limita a una anotación contable, ajena a la libre disponibilidad por parte de los administradores de la tesorería con la que cuente la sociedad para la correcta gestión y desempeño del tráfico ordinario derivado del desarrollo de la actividad de la sociedad. ${ }^{23}$

EI FRO, siendo parte del Patrimonio Neto, es el músculo financiero que dispone la empresa para autofinanciarse. Esta afirmación lo corrobora el hecho de que la dotación de esta reserva proviene, mayoritariamente, de haberse obtenido resultados positivos - beneficiosdurante los ejercicios económicos anteriores. Ahora bien, igual que la circunstancia de que se generen unas pérdidas no va irremediable-

23 Gadea Soler, E. «Equilibrio entre el mantenimiento de la identidad cooperativa y el adecuado tratamiento del Fondo de Reserva Obligatorio (FRO)». Sociedad y utopía: Revista de ciencias sociales, núm. 40, 2012, p. 260. 
mente ligado a que la empresa tenga deudas pendientes de liquidar, sino que se deriva del hecho de que los gastos han superado a los ingresos, la dotación del FRO tampoco implica la imposibilidad de hacer uso de esas cantidades en la gestión del día a día de la sociedad. Se trata de un concepto también contable, sujeto al riesgo empresarial. De esta manera, ni un resultado de pérdidas conlleva necesariamente tener deudas no atendidas, siendo aquél un concepto contable, ni el hecho de tener un FRO conlleva que esas «deudas» deban ser atendidas por la cooperativa a través de las cantidades dotadas en cumplimiento de la legislación vigente a favor de dicha Reserva, tal y como ya advertíamos con anterioridad.

El mencionado Fondo, a cuanto regula el art. 71 de la LCE, se dota de varios recursos, concretamente de los resultados positivos del ejercicio económico, de las deducciones sobre las aportaciones al capital en caso de baja del socio y de las cuotas de ingreso. A continuación, se profundizará en éstas últimas, puesto que al ser elementos patrimoniales aportados directamente por los socios persiguen la finalidad de investigación de este trabajo.

A este respecto las cuotas de ingreso se definen como el desembolso adicional que se exige realizar al nuevo socio con el fin de impedir o aminorar la consecuencia de que su incorporación disminuya la relación entre el patrimonio neto y los socios anteriores. ${ }^{24} \mathrm{El}$ problema legislativo en relación a estas cantidades es la diversidad de criterios de limitación de este concepto. ${ }^{25}$ Por poner un ejemplo, la LCE no tiene en consideración la cuantía de las reservas, disponiendo solamente en su art. 68.2 que "Las cuotas de ingreso no podrán ser superiores al veinticinco por ciento de la aportación obligatoria al capital social vigente en cada momento para adquirir la condición de persona socia», mientras que la Ley de Cooperativas de la Comunidad Valenciana (en adelante "LCCV») toma en consideración la Reserva Obligatoria a la hora de limitar la cuota de ingreso en los casos en los que los estatutos de la cooperativa no determinen la cuantía de ésta.

Por otra parte, la LCE mantiene la denominación de Contribución para la educación y promoción cooperativa y otros fines de interés público (en adelante COFIP) que ya adquirió en base a la Disposición Adicional Cuarta de la Ley 6/2008, de 25 de junio, de la Sociedad

24 Vargas Vasserot, C., Gadea Soler, E. y Sacristán Bergia, F. Derecho de las sociedades cooperativas. Régimen económico, integración, modificaciones estructurales y disolución, La Ley, Madrid, 2017, p. 77.

25 Ibid., p. 77. 
Cooperativa Pequeña de Euskadi, para referirse al antiguo Fondo de Educación y Promoción Cooperativa ${ }^{26}$. Todo ello como contribución obligatoria que se dedica para una serie de finalidades expresamente tipificadas en el art. 72, como son la formación, la intercooperación y la promoción socio-cultural, y más concretamente:

a) La formación y educación de sus personas socias y personas trabajadoras sobre el cooperativismo, actividades cooperativas y otras materias no relacionadas con el puesto de trabajo.

b) La promoción de las relaciones intercooperativas, incluyendo la cobertura de gastos por la participación en entidades creadas para la promoción, asistencia, dirección común o actividades de apoyo entre cooperativas.

c) La promoción educativa, cultural, profesional y asistencial, así como la difusión de las características del cooperativismo en el entorno social en que se desenvuelva la cooperativa y en la sociedad en general.

d) La promoción del uso del euskera.

e) La promoción de nuevas empresas cooperativas mediante aportaciones dinerarias a una entidad sin ánimo de lucro promovida por el movimiento cooperativo vasco.

f) La formación y educación de las personas socias y trabajadoras para el fomento en las sociedades cooperativas de una política efectiva para avanzar hacia la igualdad de mujeres $y$ hombres.

Las aportaciones que se realizan a este Fondo son los resultados positivos del ejercicio, en el porcentaje mínimo legalmente establecido (art. 70.2 de la LCE), la plusvalía que pudiera resultar de la regularización del balance, en su caso, (art. 64.2 de la LCE) y las sanciones económicas que la cooperativa imponga a sus socios (a tenor del art. 72.4 de la LCE). Sanciones que, en su caso, deberán obligatoriamente figurar recogidas en los Estatutos Sociales, junto con la relación de eventuales infracciones de las que podrían derivarse aquéllas; todo ello junto al procedimiento sancionador, a tenor de cuanto dispone el art. 29 de la LCE.

No siendo objeto del presente artículo el análisis profuso de las particularidades que rodean a este Fondo, que se estima son lo suficiente-

26 Ómez De la Iglesia, R. El Fondo de Educación y Promoción Cooperativa: una visión desde el patrocinio empresarial, Federación de Cooperativas de Trabajo Asociado en Euskadi, Vitoria-Gasteiz, 1994, p. 47. 
mente abundantes como para justificar otro artículo, sí debemos reparar, necesariamente, en el hecho de que la propia regulación contenida en la LCE advierte que:

a) La cooperativa no tendrá poder de disposición sobre esta contribución, más allá de destinarla a las finalidades de interés público anteriormente enunciadas y, consecuentemente

b) Es inembargable.

A diferencia de cuanto se estipula respecto al FRO, cuya dotación resulta «meramente» contable, pudiendo los administradores destinar los referidos importes dotacionales del fondo a sufragar, como parte de la tesorería de la sociedad, los gastos derivados de la gestión y representación de ésta, la LCE establece que las cantidades destinadas a o que forman parte del COFIP sólo pueden aplicarse a las finalidades expresamente reguladas por la LCE. En relación al control del destino del COFIP, el art. 14.4 del Decreto 58/2005, de 29 de marzo, por el que se aprueba el Reglamento de la Ley de Cooperativa de Euskadi (en adelante «Reglamento de la LCE»)27, establece la obligatoriedad de recoger en el informe de gestión o, en su caso, en la memoria de la cooperativa «las cantidades que con cargo a dicho fondo se hayan destinado a los fines del mismo», debiendo señalarse las actividades de interés público que se hayan realizado con éstas.

Por otro lado, y también en contraste al FRO, el COFIP es inembargable (aspecto en el que se profundizará en el quinto epígrafe del presente artículo), hecho que deviene de la falta de poder de disposición de la cooperativa sobre este último Fondo, tal y como ya adelantábamos. Es decir, además de que los administradores de la sociedad vengan obligados a gestionar el COFIP atendiendo a los límites de interés público tasados por la LCE y estén obligados a rendir cuentas sobre la gestión de dicho fondo, dicha ley viene a proteger las cantidades depositadas en éste de posibles embargos de acreedores. Aunque, tal y como analizaremos más adelante, esto no significa que sus dotaciones estén protegidas ante cualquier situación, ya que la cooperativa podría venir obligada a responder por las deudas contraídas para la realización de las finalidades de interés público recogidas en el art. 72 de LCE con cargo a los importes dotacionales del COFIP, aun cuando no hubiera sido esa su pretensión inicial, en caso de no disponer patrimonio suficiente para satisfacer dichas deudas.

27 Entendemos que el Decreto 58/2005 sigue vigente, no integrándose dentro de los supuestos enumerados en la Disposición Derogatoria de la reciente LCE ya que no se opone a lo establecido en esta última. 
Finalmente, señalar en relación a la partida de balance que se deriva de la cuenta de explotación (pérdidas y ganancias), es decir, el resultado del ejercicio con reflejo en el Patrimonio Neto de la sociedad, que no cobra especial relevancia en las cooperativas de viviendas por su finalidad en sí. Por lo común, esta clase de cooperativas no tienen por objeto la especulación habitual y casi inherente al hecho promocional en el que se basa el sector inmobiliario ni, consecuentemente, la distribución de resultados positivos, sino más bien todo lo contrario; evitar sobrecostes derivados de la participación de intermediarios, procurando su autopromoción.

En todo caso, sí se estima interesante remarcar la práctica habitual que resulta en las cooperativas de viviendas respecto a la cuenta de explotación. Así, durante la vida y el desarrollo de la ejecución de la promoción, y hasta la efectiva adjudicación —escrituración- de los elementos promovidos, la cuenta de explotación (resultado del ejercicio) se tiende a igualar a cero, aprovechando la posibilidad que otorgan las normas de contabilidad 28 , de activar como "existencias» (activo) todos los gastos en los que hubiera incurrido la sociedad en el ejercicio de su actividad promocional durante el ejercicio económico. Recogiéndose los ingresos, fundamentalmente cantidades desembolsadas por los socios a cuenta de la vivienda, como partida acreedora (pasivo). Será el momento de la efectiva adjudicación - escrituración y transmisión de la titularidad de los elementos promovidos - cuando aflore el verdadero resultado de la sociedad, derivada de su actividad promocional.

\section{El embargo de los bienes y derechos en el Código Civil: breve acercamiento}

El art. 1.911 del Código Civil (en adelante "CC») establece que el deudor responde de sus obligaciones universalmente, es decir, «con todos sus bienes, presentes y futuros». Aun así, este precepto se ve limitado por la Ley 1/2000, de 7 de enero, de Enjuiciamiento Civil (en adelante «LEC»), concretamente por los art. 605, 606 y 607.

$\mathrm{El}$ art. 605 enumera aquellos bienes que se consideran inembargables, disponiendo que ostentarán la condición de tal los bienes y derechos accesorios declarados inalienables, los bienes que carezcan de contenido patrimonial (es decir, derechos sin carácter económico) y los

28 Orden EHA/3360/2010, de 21 de diciembre, por la que se aprueban las normas sobre los aspectos contables de las sociedades cooperativas. 
bienes declarados inembargables por disposición legal. En otras palabras, dicho precepto establece la plena y absoluta inembargabilidad de esos bienes, con independencia de su valor, cantidad o titular de éstos. En cuanto a la regulación de la inembargabilidad total de bienes determinada por disposición ajena a la LEC, se deduce que solo cabe regularizarla mediante normas de rango de ley, debido al término "disposición legal» empleado en el art. 605.29

Por otra parte, el art. 606 detalla otros bienes o derechos considerados relativamente inembargables ${ }^{30}$, esto es porque, por una parte, tienen las condiciones necesarias para ser objeto de embargo debido a su contenido patrimonial y alienabilidad pero, por otra parte, con el fin de proteger los derechos del ejecutado por intereses que el legislador estima conveniente salvaguardar, la LEC determina la total o parcial inembargabilidad de estos bienes o derechos:

1. ${ }^{\circ}$ El mobiliario y el menaje de la casa, así como las ropas del ejecutado y de su familia, en lo que no pueda considerarse superfluo. En general, aquellos bienes como alimentos, combustible y otros que, a juicio del tribunal, resulten imprescindibles para que el ejecutado y las personas de él dependientes puedan atender con razonable dignidad a su subsistencia.

2. ${ }^{\circ}$ Los libros e instrumentos necesarios para el ejercicio de la profesión, arte u oficio a que se dedique el ejecutado, cuando su valor no guarde proporción con la cuantía de la deuda reclamada.

3. ${ }^{\circ}$ Los bienes sacros y los dedicados al culto de las religiones legalmente registradas.

4. ${ }^{\circ}$ Las cantidades expresamente declaradas inembargables por Ley.

5. ${ }^{\circ}$ Los bienes y cantidades declarados inembargables por Tratados ratificados por España.

Por último, el art. 607 establece la inembargabilidad de «el salario, sueldo, pensión, retribución o su equivalente, que no exceda de la cuantía señalada para el salario mínimo interprofesional», protegiendo la ley incluso las cantidades que excedan de ese límite, estableciendo

29 Salinas Molina, F. «Bienes absolutamente inembargables». En: El proceso civil VI, Tirant lo blanch, Valencia, 2001, tomado de Tirant online:

https://www.tirantonline.com/tol/documento/show/71884?index=5\&librodoctrina=2 297\&general=bienes+inembargables\&searchtype=substring.

30 Salinas Molina, F. «Bienes inembargables del ejecutado». En: El proceso civil VI, Tirant lo blanch, Valencia, 2001, tomado de Tirant online:

https://www.tirantonline.com/tol/documento/show/71885? index=16\&librodoctrina= 2297\&searchtype=substring 
el art. 607.2 una escala determinando los porcentajes aplicables a las sumas que rebasen dicho margen, como máximo hasta el 90 por 100, siendo embargable solo la cantidad resultante.

La razón de ser de la inembargabilidad de dichos bienes y derechos radica, como bien explica el Tribunal Constitucional en su Sentencia 113/1989 de 22 de junio de 1989 (Cuestión de Inconstitucionalidad n. ${ }^{\circ}$ 68/1985) en su Fundamento Tercero:

«Entre esas variadas razones que motivar, las declaraciones legales de inembargabilidad, bastante numerosas en nuestro Derecho vigente, destaca la social de impedir que la ejecución forzosa destruya por completo la vida económica del ejecutado y se ponga en peligro

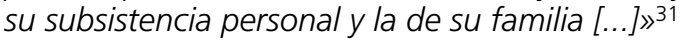

Cabe señalar en relación a lo pronunciado por el Tribunal Constitucional que, aunque la LEC dote de protección a bienes y derechos necesarios para el desarrollo de una vida digna del ejecutado y, por ende, su familia, también ha excluido de esta protección algunos bienes o derechos imprescindibles para la subsistencia personal del deudor y el hecho familiar, como es el caso de declarar la inembargabilidad de la vivienda habitual. 32

Resulta de especial relevancia, atendiendo a la vinculación al hecho familiar (unidad convivencial) que habitualmente lleva aparejado la condición de socio de una cooperativa de viviendas, tal y como advertíamos ya en la introducción, el hecho de que el artículo 606 toma en consideración los bienes necesarios para la subsistencia, tanto personal del deudor como la de su familia, estableciendo la inembargabilidad de bienes concretos como mobiliario, ropas necesarias y alimentos, entre otros.

El embargo de bienes considerados inembargables será nulo de pleno derecho, en base al art. 609, permitiendo al embargado denunciar este hecho ante los tribunales.

Para finalizar con el presente apartado, el art. 588.1 del Código Civil establece la nulidad del embargo indeterminado, es decir, el embargo realizado sobre bienes y derechos cuya efectiva existencia no conste. Con la limitación que establece el art. 588.2 «podrán embargarse los depósitos bancarios y los saldos favorables que arrojaren las cuentas abiertas en entidades de crédito, siempre que, en razón del título ejecutivo, se determine por el Letrado de la Admi-

31 STC 113/1989 de 22 de junio de 1989 , F.j.3., n. 68/1985, Ref. La Ley, 314-JF/0000.

32 Salinas Molina, F. "Bienes absolutamente inembargables...», op. cit. 
nistración de Justicia una cantidad como límite máximo.» Si los fondos se encuentren depositados en cuentas a nombre de varios titulares solo se embargará la parte correspondiente al deudor.

\section{Embargabilidad de las aportaciones y fondos obligatorios en las cooperativas de viviendas de Euskadi}

En primer lugar, quisiéramos señalar que es objeto del presente punto el de procurar el análisis de la embargabilidad del patrimonio de las sociedades cooperativas de viviendas, tomando como referencia patrimonial no sólo el Patrimonio Neto en sí, sino también las cantidades entregadas a cuenta de adjudicación de vivienda por parte de los socios, por cuanto en la práctica resultan parte fundamental de la financiación de la actividad promocional, junto con la financiación externa (préstamo promotor facilitado por las entidades financieras). Y ello porque, tratándose de una autopromoción, son precisamente los desembolsos realizados por los socios los que, a la postre, procuran la liquidación de todos los gastos originados, incluidos los gastos financieros derivados del eventual préstamo promotor que se hubiera podido formalizar con la finalidad de facilitar aquéIla; sin perjuicio de la habitual ulterior transformación total o parcial del mismo en préstamos hipotecarios individualizados de cada socio, convertido ya en propietario de los elementos de los que hubiera resultado adjudicatario.

Es por ello que procederemos, en primer lugar, al análisis de la embargabilidad o no de las cantidades reflejadas en las cuentas que conforman el Patrimonio Neto (capital social, FRO y COFIP), para finalizar con el estudio de la eventual embargabilidad de las cantidades entregadas a cuenta de adjudicación de vivienda por parte de los socios, y que figuran en el pasivo del balance, dentro de una partida acreedora por desembolsos de los propios socios.

Una vez matizada la finalidad perseguida por quienes suscriben, y comenzando el análisis acerca de la supuesta embargabilidad de las aportaciones al capital social de la sociedad, como anteriormente se ha señalado, éstas se integran en el patrimonio de la cooperativa y comportan un riesgo quedando reflejados en el balance de la cooperativa dentro del patrimonio.

Atendiendo a la ubicación del capital social, varias leyes autonómicas junto a la ley de cooperativas estatal (Ley 27/1999, de 16 de julio, de Cooperativas), establecen la inembargabilidad por parte de los acreedores personales de los socios de las aportaciones realizadas por 
éstos. Ahora bien, todo ello sin perjuicio del derecho de los mencionados acreedores a ejercer acciones procurando la compensación de sus créditos con cargo a los eventuales reembolsos, intereses y retornos que pudieran corresponderle al socio. ${ }^{33}$ Criterio que viene reforzado por la Doctrina. ${ }^{34}$

La antigua Ley 4/1993, de 24 de junio, de Cooperativas de Euskadi no se pronuncia al respecto. Sin embargo, la reciente LCE en su art. 65.2 sí regula este aspecto de manera idéntica a las leyes autonómicas citadas, disponiendo:

«Los acreedores personales de las personas socias no tendrán derecho alguno sobre los bienes de las cooperativas ni sobre las aportaciones de las personas socias al capital social, que son inembargables. Todo ello, sin menoscabo de los derechos que pueda ejercer el acreedor o acreedora sobre los reembolsos, intereses y retornos que correspondan a la persona socia.»

Por lo que corresponde a las reservas obligatorias, éstas se dotan tangencialmente de las aportaciones de los socios, y principalmente como resultado de la aplicación de cuanto dispone el art. 70 de la LCE respecto al destino, que debe procurar mínimamente la cooperativa de los resultados positivos que pudiera obtener a la finalización de cada ejercicio económico. Debemos reseñar que la calificación como tangencial de la relevancia de las aportaciones de los socios a dichos fondos se debe básicamente a su carácter residual. Y ello porque solo procede dicha dotación en caso de aplicación de deducciones para los supuestos de baja no justificada y desembolso de cuotas de ingreso para adquirir la condición de socio (con destino al FRO), y las sanciones económicas que pudieran imponerse a los socios como consecuencia de la comisión de infracciones (con destino al COFIP). Importes en todo caso normalmente simbólicos, por cuanto ni las aportaciones obligatorias para adquirir la condición de socio sobre las que se aplicarían las deducciones, atendiendo en todo caso a los límites legalmente establecidos ${ }^{35}$, resultan

33 Véase: Decreto-Ley 2/2015, de 15 de mayo, por el que se aprueba el texto refundido de la Ley de Cooperativas de la Comunitat Valenciana, art. 60.6; Ley 4/1999, de 30 de marzo, de Cooperativas de la Comunidad de Madrid, art. 54.6; Ley 27/1999, de 16 de julio, de Cooperativas, disposición adicional tercera.

34 Véase: Torres Pérez, F.J. Régimen de las aportaciones sociales en la Sociedad Cooperativa. Tesis doctoral. Universidad de Vigo, Vigo, 2011, p. 138 [consulta:23 de octubre de 2019]. Disponible en web: http://www.investigo.biblioteca.uvigo.es/xmlui/ handle/11093/315.

35 Art. 66.1 de la LCE. 
relevantes, como ya señalábamos con anterioridad; ni resulta habitual el requerimiento de desembolso de cuotas de ingreso para adquirir la mencionada condición de socio, que, en todo caso, se encuentra también limitado, al igual que las deducciones referidas, al importe de la aportación obligatoria; y rara vez se imponen sanciones pecuniarias a los socios por la comisión de alguna infracción legal o estatutariamente prevista, requiriendo además las sanciones por infracciones graves y muy graves, económicamente más destacables, de la oportuna tramitación de expediente disciplinario, con la dificultad jurídico-procesal que de tal hecho se deriva para la propia sociedad cooperativa y sus administradores, lo que lo convierte, en la práctica, en un procedimiento muy poco atractivo y, por ende, eficaz. Todo lo cual exponemos sin perjuicio de reiterar que los resultados económicos de las cooperativas de viviendas durante el desarrollo de la actividad promocional y hasta el ejercicio de la efectiva adjudicación - escrituración - de los elementos promovidos tienden a ser cero. Consecuentemente, durante la vida de la actividad promocional entendida en sentido estricto estas cooperativas o bien no tienen constituidos fondos obligatorios, por falta de dotación, o si se encuentran constituidos lo están por importes dotacionales insignificantes. Cuestión distinta es la dotación económica que pudiera derivarse a favor de dichos fondos obligatorios como consecuencia de aplicar al resultado positivo que hubiere podido obtener la cooperativa a la finalización del ejercicio en el que se produjera la efectiva adjudicación de los elementos promovidos, tanto a favor de los socios adjudicatarios como, en su caso, de terceros ${ }^{36}$, aquellos porcentajes de distribución establecidos por el art. 70 de la LCE. Es decir, aflorando a cierre del referido ejercicio económico un diferencial positivo entre los ingresos obtenidos fruto de la adjudicación (socios) y/o enajenación (terceros) de los elementos promovidos, y los gastos en los que hubiera incurrido la sociedad para, precisamente, poder llevar a cabo la ejecución - actividad promocional de los elementos mencionados.

La Ley Vasca establece consecuencias divergentes en cuanto a la posibilidad de embargo según la reserva. Con respecto al FRO la LCE, como la Ley estatal y las leyes autonómicas, no establece la inembargabilidad de éste, por lo que, aparte de poder imputar a este Fondo las pérdidas del ejercicio, se podría concluir que las cuotas de ingreso de los socios podrán ser objeto de embargo por los acreedores de la cooperativa.

36 Art. 117.2 de la LCE. 
En consideración a la supuesta embargabilidad del COFIP, la LCE deja claro en su art. 72.2 que es inembargable debido a que «la cooperativa no tiene poder de disposición sobre esta contribución.» La inembargabilidad de este Fondo está generalizada a las demás leyes autonómicas, como es el caso de la Ley 12/2015, de 9 de julio, de cooperativas de la Comunidad Autónoma de Cataluña (art. 85.3), la Ley 14/2011, de 23 de diciembre, de Sociedades Cooperativas Andaluzas (art. 71.1) y el Decreto Legislativo 2/2015, de 15 de mayo, del Consell, por el que se aprueba el texto refundido de la LCCV (art. 72.3), e incluso la ley estatal (art. 56.5) de aplicación única y exclusivamente subsidiaria para lo no regulado por las legislaciones autonómicas, tal y como ya advertíamos con anterioridad, señala expresamente el carácter inembargable del COFIP.

A diferencia de la Ley 4/1999, de 30 de marzo, de Cooperativas de la Comunidad de Madrid (art. 64.4) y de la ley estatal (art. 56.6), entre otras, la LCE no establece la prohibición de que los depósitos bancarios o los títulos de deuda pública de la Comunidad Autónoma del País Vasco (art. 14.3 del Reglamento de la LCE) en los que se materialice esta reserva sean pignorados o afectados a cuentas de crédito o préstamos. Estos contratos bancarios (depósitos bancarios) y títulos-valores (títulos de deuda pública) en los que se puede materializar el COFIP proporcionan seguridad, liquidez y rentabilidad a la cooperativa y a sus socios. Por lo cual, el hecho de no establecer esta prohibición puede originar consecuencias en sentido contrario, debido a que la Reserva podría estar vinculada a un derecho de crédito u obligación de pago, los cuales pueden acarrear que el acreedor solicite el embargo de las cantidades depositadas en el Fondo en caso de no ver satisfecha su deuda, cuando a tenor del art. 72.3 de la LCE éste es inembargable.

A su vez, la LCE no regula, a diferencia de, por ejemplo, la ley estatal (art. 64.4) y la LCCV (art. 72.5), la obligatoriedad de expresar la inembargabilidad de bienes inmovilizados en el Registro de la propiedad, o en aquél en el que el bien se halle inscrito, si el fondo o parte de éste se aplicase en estos bienes. Nuevamente, esto puede ocasionar problemas en cuanto a la seguridad del Fondo, ya que los acreedores podrían exigir el embargo del bien afecto a éste y, en caso de no ver satisfechos sus créditos, ejercer su derecho a reclamar la realización del embargo del bien, acción que es contraria al precepto regulado en el art. 72.3 de la LCE sobre la inembargabilidad del Fondo.

Estas disposiciones son una garantía para la inembargabilidad de dicha Reserva Obligatoria. Aun así, esto no significa que el legislador vasco no haya procurado la referida garantía por otros medios, como 
es el caso de controlar el destino de este Fondo mediante el informe de gestión regulado en el art. 14.4 del Reglamento de la LCE.

Para finalizar, el artículo 59.1 de la LCE deja claro que, respecto al COFIP, las cantidades desembolsadas por los socios a este Fondo, concretamente las sanciones disciplinarias impuestas por la cooperativa a éstos, solo podrán verse afectadas por las obligaciones contraídas para el cumplimiento de los fines del COFIP. Esta regulación establece un blindaje en relación a dicho Fondo ${ }^{37}$.

A efectos prácticos, en el supuesto de que el patrimonio de la cooperativa no fuera suficiente para responder de las deudas de los acreedores, éstos no podrán dirigirse contra la sociedad para satisfacer su crédito con cargo a los importes dotacionales del COFIP, a no ser que esa deuda trajera causa precisamente de la realización de alguno de los propósitos y finalidades legalmente enmarcadas para dicho Fondo como, por ejemplo, debido a la creación de infraestructuras para la formación, gastos de participación en un grupo corporativo de una cooperativa, edición de publicaciones, pagos a las entidades asociativas de sus respectivas cuotas... Y ello sin perder nunca de vista, además, la absoluta libertad de los administradores y de la cooperativa para acordar la liquidación de aquéllas deudas que pudieran enmarcarse incluso dentro del ámbito de aplicabilidad del Fondo, con cargo al COFIP, o a través de otros medios.

Debemos aclarar también que, para el supuesto contrario, es decir que los importes dotaciones del COFIP fueran insuficientes para hacer frente a las obligaciones contraídas para el cumplimiento de los fines de éste, se estima que los acreedores sí que podrían dirigirse contra el resto del patrimonio cooperativo. ${ }^{38}$

Entendemos por tanto que el legislador autonómico ha atendido a las particularidades de las dotaciones y finalidades perseguidas a través de la aplicabilidad del COFIP, y que ha sido congruente, procurando una mayor clarificación respecto a su inembargabilidad, reforzando aspectos que con la regulación anterior pudieran quedar en tela de juicio, sin perjuicio de que el legislador no haya entrado a regular la total casuística que podría darse. Todo ello sin perjuicio de las distintas interpretaciones jurídicas que puedan desprenderse de la materia estudiada.

Resumiendo, en cuanto a las cantidades integradas en los fondos de reserva obligatorias estimamos manifiesto concluir el carácter embargable del FRO y la naturaleza inembargable del COFIP, sin perjuicio

37 El art. 56 de la anterior Ley 4/1993, de 24 de junio, de Cooperativas de Euskadi, el cual regulaba la responsabilidad por las deudas sociales, no ofrecía dicha garantía.

38 Fajardo García, G. La gestión económica... op. cit., p. 477. 
tanto de la falta de una coincidencia íntegra entre las finalidades perseguidas por el legislador vasco, frente a otras realidades legislativas autonómicas, como, sobre todo, de una regulación más específica en materia de garantías, como por ejemplo la prohibición de pignorar o afectar a préstamos o cuentas de crédito. La inembargabilidad es consecuencia de los límites legalmente establecidos al poder de disposición a la sociedad, poder que permite a los administradores disponer de la parte líquida (tesorería) de la que forme parte el FRO para el desarrollo de la actividad ordinaria, no así de los importes que formen parte del COFIP.

Por último, en relación con la embargabilidad de las cantidades entregadas a cuenta para adjudicación de vivienda, lo más relevante es saber si se integrarán en el patrimonio de la cooperativa o si seguirán en el patrimonio del socio. Por una parte, puede que las cantidades se integren en el patrimonio cooperativo, supuesto que lo posibilitan varias leyes autonómicas, al establecer que a través de los estatutos se pueda acordar que dichas aportaciones sí integren el patrimonio cooperativo. ${ }^{39}$

Su ubicación tiene gran importancia, ya que la masa que sea propiedad del socio no responderá frente a los acreedores sociales de la cooperativa, y la que es propiedad de la cooperativa estará a salvo de los acreedores personales de los socios. ${ }^{40}$ Por todo ello, en caso de que las cantidades entregadas ingresen en el patrimonio de la cooperativa, los acreedores sociales de la cooperativa podrán reclamar de esa cantidad su crédito correspondiente, al contrario de los acreedores personales del socio.

Respecto a la posibilidad de integrar estas cantidades en el patrimonio cooperativo, no tiene relevancia para el acreedor personal del socio, ya que la cooperativa, al disponerlas a título fiduciario, podría utilizarse para el pago de deudas. ${ }^{41}$

Por otra parte, la LCE en su art. 68.3 estipula que las cantidades entregadas a cuenta no integran el patrimonio cooperativo, prohibiendo que puedan ser embargadas por los acreedores sociales de la cooperativa:

39 Véase: Ley 4/1999, de 30 de marzo, de Cooperativas de la Comunidad de Madrid, art. 57.2; Decreto-Ley 2/2015, de 15 de mayo, por el que se aprueba el texto refundido de la Ley de Cooperativas de la Comunitat Valenciana, art. 64.3; Ley 11/2010, de 4 de noviembre, de Cooperativas de Castilla-La Mancha, art. 83.2.

40 Fajardo García, G. La gestión económica... op. cit., p. 220.

41 González Tausz, R. «Las cooperativas de viviendas de responsabilidad limitada no existen». Revesco: Revista de Estudios Cooperativas. 1.er cuatrimestre 1999, n. ${ }^{\circ} 67$, p. 118. 
«La entrega por las personas socias de cualquier tipo de bienes o la prestación de servicios para la gestión cooperativa y, en general, los pagos para la obtención de los servicios cooperativos no integran el capital social y están sujetos a las condiciones fijadas y contratadas con la cooperativa. Aquellas entregas no integran el patrimonio de la cooperativa, y no podrán ser embargadas por los acreedores sociales.»

Entendemos que el mencionado artículo no habilita la posibilidad de integrar las cantidades entregadas a cuenta de adjudicación de vivienda por los socios en el patrimonio de la cooperativa, al contrario de cuanto expresamente disponen otras leyes autonómicas. Es por ello que, en base a la regulación contenida en la LCE, se estima que las cantidades desembolsadas por los socios a cuenta de la futura adjudicación de su vivienda deben considerarse como parte integrante e inseparable del patrimonio personal de los mismos, debiendo contabilizarlas la cooperativa como tales, en una cuenta acreedora de su pasivo. ${ }^{42}$

En este mismo sentido se pronuncia parte importante de la doctrina al defender la interpretación de que si las cantidades entregadas a cuenta no integran, basándonos en lo estipulado en el art. 68.3 de la LCE, el Patrimonio Neto de la cooperativa, los acreedores personales del socio podrán embargar dichas cantidades para satisfacer su crédito, sin perjuicio de privar de esta posibilidad a los acreedores sociales de la cooperativa. Acreedores sociales que verán sus acciones reivindicatorias limitadas al patrimonio de la cooperativa, conformado, entre otros, por su capital social y su bienes. ${ }^{43}$ De esta manera, la práctica habitual de la identificación de los elementos de los que resultare adjudicatario cada socio al inicio de la actividad promocional —ejecución de la obra-y, más concretamente, en el marco de la formalización del pertinente contrato de adjudicación, viene a reforzar la interpretación de la embargabilidad de las cantidades entregadas a cuenta de la futura adjudicación. Pero no podemos obviar en este sentido que el socio adquiere también, normalmente al mismo tiempo de la formalización de aquel contrato de adjudicación, una serie de obligaciones socio económicas para con la cooperativa, cuyo vencimiento resulta igualmente anticipado a la efectiva adjudicación -escrituración. Es por ello que los de-

42 Vargas Vasserot, C. «El derecho del socio en caso de baja y el concurso de las sociedades cooperativas». CIRIEC-España. Revista jurídica de economía social y cooperativa. 2010, n. ${ }^{\circ} 21$, p. 48.

43 Defienden este criterio Torres Pérez, F.J. Régimen de las aportaciones... op. cit., pp 138-139; Fajardo García, G. La gestión económica... op. cit, p. 203; y González Tausz, R. "Las cooperativas de viviendas...», op. cit, p. 118; Vargas Vasserot, C. «El derecho del socio...» op. cit., p. 49. 
rechos de la cooperativa frente a los socios que la conforman derivados de los citados compromisos socio económicos adquiridos por éstos no puedan resultar perjudicados por aquella embargabilidad. ${ }^{44}$

Por lo cual, al tiempo que la LCE (art. 65.2) disipa la duda sobre la embargabilidad de las aportaciones de los socios al capital social que provocaba la regulación contenida en la antigua Ley 4/1993, de 24 de junio, de Cooperativas de Euskadi (derogada por la LCE), señalando su inembargabilidad por parte de los acreedores personales de los socios, sigue sin aclarar de manera expresa la eventualidad del embargo por parte de los acreedores personales de los socios de las cantidades entregadas por éstos a cuenta de adjudicación de vivienda (o los elementos promovidos de los que hubiere resultado adjudicatario), y que no forman parte del capital social. Compartiendo el criterio jurídico-contable doctrinal relativo a que dichas cantidades no forman parte del capital social ni, por ende, del Patrimonio Neto de la sociedad, no podemos participar de las conclusiones contenidas en otras legislaciones autonómicas en este sentido, además de por lo ya expuesto, porque estimamos lógico concluir que si el legislador de la LCE no lo ha recogido así ha sido de manera intencionada, a diferencia de cuanto ha procurado respecto a las aportaciones a capital social, y porque tampoco lo dispone la ley estatal, en lo que pudiera conllevar una aplicación supletoria.

En base a todo lo expuesto, si bien podría concluirse el eventual interés de los socios adjudicatarios para que todos sus desembolsos previos al momento de la efectiva adjudicación de los elementos promovidos pudieran computarse como aportaciones a capital social, al objeto de su calificación como inembargables por parte de los acreedores personales, no debemos olvidar tampoco que la Cooperativa responde con su capital social frente a sus acreedores sociales. Al tiempo que dicha práctica también conllevaría repercusión fiscal irremediablemente vinculada a las autoliquidaciones del IVA que pudiera llevar a cabo la cooperativa. Es por ello que para la debida calificación jurídico-económica de las cantidades desembolsadas por los socios se deberá atender, caso por caso, al hecho de si aquéllas llevan o no aparejada de alguna manera, ya sea explícita o implícita, la transmisión de los derechos sobre los elementos promovidos. ${ }^{45}$

44 Véase: FAJARDO GARCÍA, G. La gestión económica... op. cit, p. 216; TORRES PÉREZ, F.J. Régimen de las aportaciones... op. cit., p. 139.

45 PANIAGUA ZURERA, M. La sociedad cooperativa. Las sociedades mutuas de seguros y las mutualidades de previsión social. Madrid: Ed. Marcial Pons, Ediciones Jurídicas y Sociales, 2001, p. 251, tomado de VARGAS VASSEROT, C. «El derecho del socio... op. cit., p. 49. 


\section{Conclusiones}

Primera. Debemos destacar de entre las especificidades de las cooperativas de viviendas, respecto al resto de clases de cooperativas, las siguientes:

- La existencia de desembolso de cantidades por parte de los socios adjudicatarios que no van destinadas al capital social como aportaciones, ni obligatorias ni voluntarias, sino a cuenta de adjudicación de la futura vivienda. Y por ello, sujetas al tipo impositivo correspondiente del IVA.

- La posibilidad de la activación como «existencias» en el balance de situación de todos los gastos en los que vaya incurriendo la sociedad en el desarrollo de su actividad promocional hasta el ejercicio de la efectiva adjudicación y enajenación -escrituración- de los elementos promovidos. Es decir, procurándose de esta manera el cierre — cuenta de explotación — de los ejercicios económicos señalados a cero.

Segunda. Atendiendo al régimen económico dotacional legalmente establecido para los fondos obligatorios (FRO y COFIP), y como consecuencia de lo anteriormente expuesto, el estudio de los mencionados fondos no reviste sustancial trascendencia durante el período de actividad promocional - ejecución de la obra - de las cooperativas de viviendas.

Tercera. Sí resulta en cambio interesante el estudio genérico de la embargabilidad de los referidos fondos obligatorios, por la eventualidad de que pudieran aflorar cantidades dotacionales destinados a aquellos como consecuencia de un resultado económico positivo a partir del ejercicio en el que se produjera la efectiva adjudicación y/o enajenación de los elementos promovidos.

Cuarta. De esta manera, la legislación vasca regula expresamente la inembargabilidad del COFIP, debiendo entenderse el FRO como embargable por cuanto nada dispone el legislador en sentido contrario; pareciendo lógico concluir que, si así lo hubiere pretendido, no hubiera tenido más que repetir o remitirse a lo ya preceptuado en tal sentido para el primero.

Quinta. En cuanto a las aportaciones desembolsadas por los socios a la cooperativa:

- No existiendo particularidad alguna que ataña en exclusiva a las cooperativas de viviendas frente al resto de clases de cooperativas en relación a las aportaciones a capital social, sí 
resulta reseñable el hecho de que el legislador haya incorporado explícitamente en la nueva LCE el carácter inembargable de las mismas, tanto por parte de los acreedores sociales como de los personales, procurando así disipar cualquier duda que hubiera podido existir hasta la fecha como consecuencia de su falta de previsión expresa en la legislación anterior derogada.

- Con respecto a las cantidades entregadas para adjudicación de vivienda, no podemos más que concluir su embargabilidad por parte de los acreedores personales, por cuanto continúan formando parte del patrimonio de los propios socios hasta el momento de la efectiva adjudicación de los elementos promovidos de los que hubieren resultado beneficiarios. No así por parte de los acreedores sociales, dado que aquellas cantidades no pasan a formar parte del patrimonio de la cooperativa hasta tanto no se produzca la referida efectiva adjudicación - escrituración. Criterio que se estima reforzado por el hecho de que el legislador haya regulado expresamente su inembargabilidad por parte de los acreedores sociales, pareciendo lógico concluir que, si así lo hubiera pretendido también para los personales, lo hubiera recogido. Inembargabilidad que tampoco contiene en la legislación estatal, para el supuesto de que se estimare su eventual aplicación supletoria.

\section{Bibliografía}

ALZOLA BERRIOZABALGOITIA, I. y ESNAOLA ETCHEVERRY, J.M. 2008. Manual de Derecho de Sociedades Cooperativas, Universidad del País Vasco junto con el Consejo Superior de Cooperativas de Euskadi, Vitoria-Gasteiz.

COLÓN MORALES, R. 2018. "La ruta autodestructiva del cooperativismo de vivienda puertorriqueño: el problema de la pérdida de la identidad cooperativa mediante la transformación de valores de uso en valores de cambio». Boletín de la Asociación Internacional de Derecho Cooperativo, núm. 52, pp. 19-46. DOI: http://dx.doi.org/10.18543/baidc-52-2018pp19-46

ETXEZARRETA ETXARRI, A. y MERINO HERNÁNDEZ, S. 2014. "Las cooperativas de vivienda como alternativa al problema de la vivienda en la actual crisis económica». Revesco: Revista de Estudios Cooperativos, núm. 113, pp. 92-119.

FAJARDO GARCÍA, G. 1997. La gestión económica de la cooperativa: responsabilidad de los socios. Tesis Doctoral (Universidad de Valencia), Tecnos, Madrid [consulta: 23 de octubre de 2019]. Disponible en web: http://roderic.uv.es/handle/10550/38450; 
GADEA SOLER, E. 2001. Derecho de las cooperativas: Análisis de la Ley 4/1993, de 24 de junio, de cooperativas del País Vasco. Universidad de Deusto, Bilbao.

GADEA SOLER, E. 2008. Manual de Derecho de Sociedades Cooperativas. Universidad del País Vasco junto con el Consejo Superior de Cooperativas de Euskadi, Vitoria.

GADEA SOLER, E. 2012. "Equilibrio entre el mantenimiento de la identidad cooperativa y el adecuado tratamiento del Fondo de Reserva Obligatorio (FRO)». Sociedad y utopía: Revista de ciencias sociales, núm. 40, pp. 218-257.

GONDRA ELGUEZABAL, G. 2004. "Euskadiko Etxebizitza Kooperatibak (iruzkinak)». Revista Vasca de Economía Social, núm. 0, pp. 107-138.

GONDRA ELGUEZABAL, G. y BILBAO ZORROZUA, A. 2019. "Alcance del régimen de responsabilidad de los socios en las cooperativas de viviendas en Euskadi». Revista Vasca de Economía Social, núm. 16, pp. 149-166.

GONZÁLEZ TAUSZ, R. 1999. "Las cooperativas de responsabilidad limitada no existen». Revesco: Revista de Estudios Cooperativas, n. ${ }^{\circ}$ 67, pp. 89-122.

GÓMEZ DE LA IGLESIA, R. 1994. El Fondo de Educación y Promoción Cooperativa: una visión desde el patrocinio empresarial, Federación de Cooperativas de Trabajo Asociado en Euskadi, Vitoria-Gasteiz.

LAMBEA RUEDA, A. 2012. Cooperativas de viviendas. Promoción, construcción y adjudicación de la vivienda al socio cooperativo. Comares, Granada

MERINO HERNÁNDEZ, S. 2008. Manual de Derecho de Sociedades Cooperativas. Universidad del País Vasco junto con el Consejo Superior de Cooperativas de Euskadi, Vitoria.

MERINO HERNÁNDEZ, S. 2018. "Realidad de las cooperativas de viviendas en la Comunidad Autónoma del País Vasco». Revista Vasca de Economía Social. núm. 15, pp. 273-300.

PANIAGUA ZURERA, M. 2001. La sociedad cooperativa. Las sociedades mutuas de seguros y las mutualidades de previsión social. Madrid: Ed. Marcial Pons, Ediciones Jurídicas y Sociales.

PUY FERNÁNDEZ, G. 1998. «Naturaleza de los bienes susceptibles de ser aportados al capital social cooperativa andaluza». Trabajo: Revista iberoamericana de relaciones laborales. n. ${ }^{\circ}$, pp. 145-170.

SALINAS MOLINA, F. 2001. "Bienes absolutamente inembargables». En: El proceso civil VI, Tirant lo blanch, Valencia, tomado de Tirant online: https://www.tirantonline.com/tol/documento/show/71884?index=5\&librod octrina $=2297 \&$ general=bienes+inembargables\&searchtype=substring .

SALINAS MOLINA, F. 2001. "Bienes inembargables del ejecutado». En: El proceso civil VI, Tirant lo blanch, Valencia, tomado de Tirant online: https:// www.tirantonline.com/tol/documento/show/71885?index=16\&librodoctrin $a=2297$ \&searchtype $=$ substring.

TORRES PÉREZ, F.J. 2011. Régimen de las aportaciones sociales en la Sociedad Cooperativa. Tesis doctoral. Universidad de Vigo, Vigo, [consulta: 23 de octubre de 2019]. Disponible en web: http://www.investigo.biblioteca. uvigo.es/xmlui/handle/11093/315. 
TORRES PÉREZ, F.J. 2012. Régimen Jurídico de las Aportaciones Sociales en la Sociedad Cooperativa. Aranzadi, Pamplona.

VARGAS VASSEROT, C., GADEA SOLER, E. y SACRISTÁN BERGIA, F. 2017. Derecho de las sociedades cooperativas. Régimen económico, integración, modificaciones estructurales y disolución, La Ley, Madrid.

\section{Jurisprudencia}

STC 113/1989 de 22 de junio de 1989 , F.j.3., n. ${ }^{\circ}$ 68/1985, Ref. La Ley, 314$\mathrm{JF} / 0000$.

\section{Legislación}

Ley 11/2019, de 20 de diciembre, de Cooperativas de Euskadi.

Ley 12/2015, de 9 de julio, de cooperativas de la Comunidad Autónoma de Cataluña.

Decreto-Ley 2/2015, de 15 de mayo, por el que se aprueba el texto refundido de la Ley de Cooperativas de la Comunitat Valenciana.

Ley 14/2011, de 23 de diciembre, de Sociedades Cooperativas Andaluzas.

Orden EHA/3360/2010, de 21 de diciembre, por la que se aprueban las normas sobre los aspectos contables de las sociedades cooperativas.

Ley 11/2010, de 4 de noviembre, de Cooperativas de Castilla-La Mancha.

Decreto 58/2005, de 29 de marzo, por el que se aprueba el Reglamento de la Ley de Cooperativa de Euskadi.

Ley $1 / 2000$, de 7 de enero, de Enjuiciamiento Civil.

Ley 38/1999, de 5 de noviembre, de Ordenación de la Edificación.

Ley 27/1999, de 16 de julio, de Cooperativas.

Ley 4/1999, de 30 de marzo, de Cooperativas de la Comunidad de Madrid.

Ley 4/1993, de 24 de junio, de Cooperativas de Euskadi.

Ley 37/1992, de 28 de diciembre, del Impuesto sobre el Valor Añadido.

Real Decreto de 24 de julio de 1889 por el que se publica el Código Civil.

\section{Consultas administrativas}

Dirección General de Tributos consulta n. ${ }^{\circ}$ 2077/2033 de 4 de diciembre de 2003. 


\section{Derechos de autor}

El Boletín de la Asociación Internacional de Derecho Cooperativo es una revista de acceso abierto lo que significa que es de libre acceso en su integridad inmediatamente después de la publicación de cada número. Se permite su lectura, la búsqueda, descarga, distribución y reutilización legal en cualquier tipo de soporte sólo para fines no comerciales y según lo previsto por la ley; sin la previa autorización de la Editorial (Universidad de Deusto) o el autor, siempre que la obra original sea debidamente citada (número, año, páginas y DOI si procede) y cualquier cambio en el original esté claramente indicado.

\section{Copyright}

The International Association of Cooperative Law Journal is an Open Access journal which means that it is free for full and immediate access, reading, search, download, distribution, and lawful reuse in any medium only for non-commercial purposes, without prior permission from the Publisher or the author; provided the original work is properly cited and any changes to the original are clearly indicated. 